\title{
Incessant ventricular tachycardia
}

\author{
R. Prisecaru ${ }^{1}$ L. Riahi ${ }^{1}$ Y. de Greef ${ }^{1}$ D. Stockman ${ }^{1}$ B. Schwagten ${ }^{1}$
}

Published online: 25 August 2016

(C) The Author(s) 2016. This article is available at SpringerLink with Open Access.

A 65-year-old patient with paroxysmal atrial fibrillation and a normal structural heart underwent cryoballoon pulmonary vein isolation (PVI) under general anaesthesia. After PVI, adenosine $12 \mathrm{mg}$ was given as a rapid intravenous bolus to test each pulmonary vein and no dormant sleeves were documented. The transseptal sheath was withdrawn into the right atrium and afterwards from the right groin. Thereafter, the patient developed pulseless monomorphic ventricular tachycardia (Fig. 1). Subsequently, intravenous injection of amiodarone and a $\beta$ blocker were administrated and repeated cardiac defibrillations were attempted, but without sustained restoration of sinus rhythm. Inferior ST elevation was also documented.
Coronary angiography revealed diffuse coronary vasospasm (Fig. 2). After intracoronary nitrate infusion, resolution of the coronary vasospasm, complete cessation of the ventricular tachycardia and normalisation of the ST segment were noticed.

Question: What is the underling mechanism of the ventricular tachycardia from Fig. 1?

\section{Answer}

You will find the answer elsewhere in this issue.

R. Prisecaru

ralu_prisecaru@yahoo.com

1 Cardiovascular Centrum Middelheim, Antwerpen, Belgium 


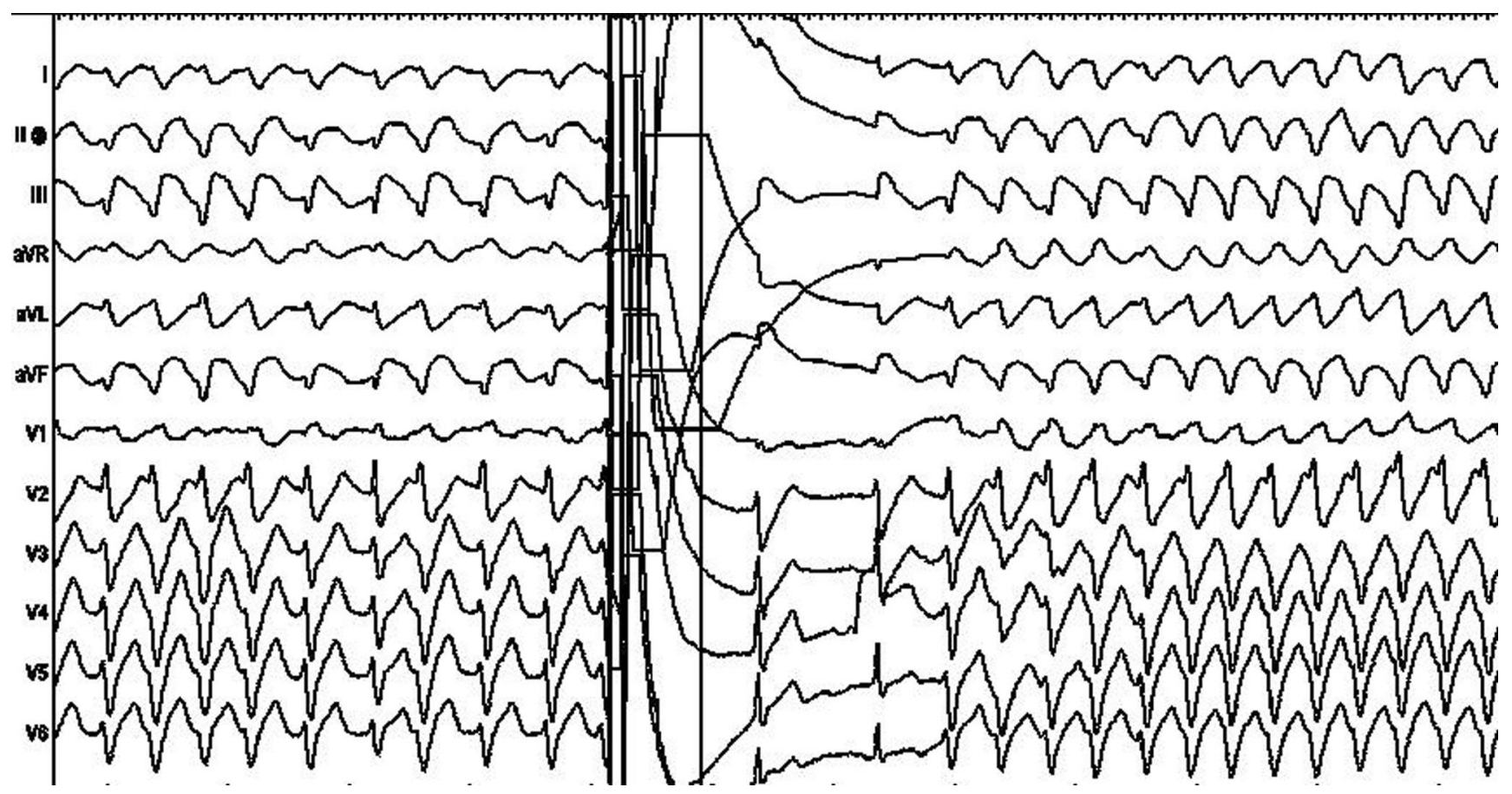

Fig. 1 Twelve-lead ECG revealing monomorphic ventricular tachycardia, followed by successful electric cardioversion and thereafter return to ventricular tachycardia

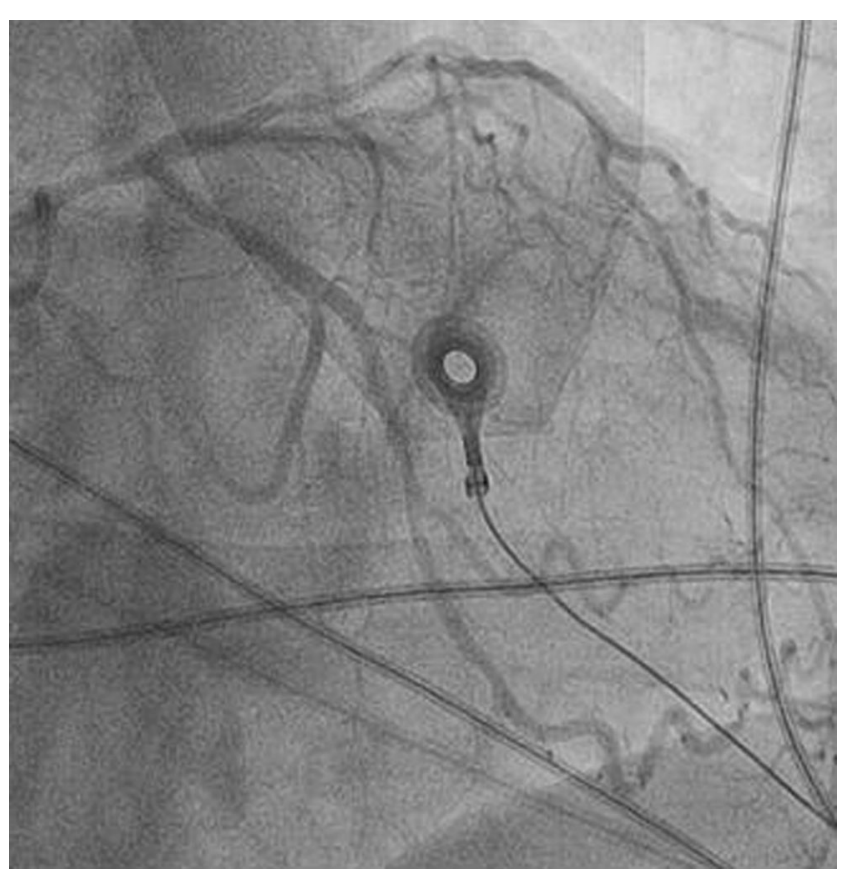

Fig. 2 Left coronary angiography showing diffuse vasospasm
Open Access This article is distributed under the terms of the Creative Commons Attribution 4.0 International License (http:// creativecommons.org/licenses/by/4.0/), which permits unrestricted use, distribution, and reproduction in any medium, provided you give appropriate credit to the original author(s) and the source, provide a link to the Creative Commons license, and indicate if changes were made. 


\section{Advertisement placed here.}

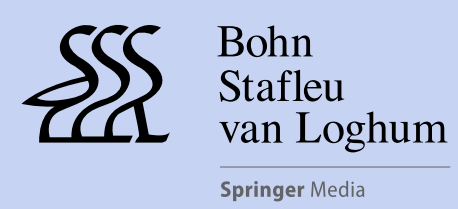

Houten 2016 


\section{Advertisement placed here.}

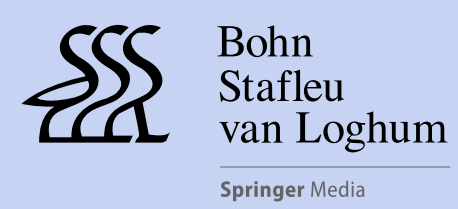

Houten 2016 